\title{
Autoconstrução, Fabricação Digital e a Construção Autônoma
}

\author{
Self-construction, Digital Fabrication and Autonomous Construction
}

\author{
Eduardo Sampaio Nardelli \\ Universidade Presbiteriana Mackenzie, Brasil \\ nardelli@mackenzie.br \\ Vinicius Juliani Pereira \\ Universidade Presbiteriana Mackenzie, Brasil \\ viniciusjulianip@gmail.com
}

\begin{abstract}
This paper aims to describe the continuity of a research on the use of the Wikihouse system to produce Social Housing in Brazil. Its main hypothesis is the possibility for the users themselves to build their houses, following the trend of Maker Movement and Self-construction, a traditional popular Brazilian movement. Specifically, it details the current stage of the this research, focused on the study of the walls of the proposed housing unit.
\end{abstract}

Keywords: Social housing, Wikihouse, Digital fabrication. Maker Movement, Self-construction

\section{Introdução}

O trabalho que ora apresentamos é a continuação parcial de uma pesquisa mais ampla, financiada pela FINEP, que se desenvolveu ao longo de seis anos, a partir de 2009, envolvendo uma rede de sete universidades brasileiras, com o objetivo de estudar as possibilidades de utilização das Tecnologias da Informação e Comunicação - TICs na produção de Habitações de Interesse Social - HIS.

Esta ampla pesquisa foi subdividida em vários subprojetos assumidos pelas universidades participantes de acordo com seus respectivos focos de interesse e disponibilidade de recursos.

No caso da Faculdade de Arquitetura e Urbanismo da Universidade Presbiteriana Mackenzie, este trabalho foi conduzido pelo Grupo de Pesquisa Teoria e Projeto na Era Digital que, dentre outros temas, optou por investigar as possibilidades de utilização da Fabricação Digital na produção das unidades habitacionais, tomando como referência os padrões definidos pelo Programa Minha Casa Minha Vida PMCMV que, àquela altura, constituía-se no maior programa habitacional em execução no país e, quiçá, no mundo e no motivador da Chamada Pública Saneamento Ambiental e Habitação 07/2009, que deu origem ao convênio.(Nardelli, 2014)

Desse modo o trabalho de pesquisa desenvolveu-se a partir desta referência sem deixar, no entanto, de abordá-la criticamente, buscando propostas que atendessem aos eventuais equívocos e/ou omissões do PMCMV.

Neste sentido destacamos a percepção, à medida em que o programa era posto em prática, de que ele não era capaz de atender as famílias de menor renda, pertencentes à faixa de 0 a 3 salários mínimos, ao mesmo tempo em que repetia equívocos do passado, ao construir grandes conjuntos de uso exclusivamente habitacional nas periferias das grandes cidades - onde a terra é mais barata - provocando assim, de um lado, o esgarçamento do tecido urbano dessas cidades e, de outro, omitindo-se na solução das chamadas favelas áreas ocupadas irregularmente pela população de baixa renda, encravadas em regiões de urbanização já consolidada. (Rolnik, 2010)

Assim, desde o início, a pesquisa estabeleceu como foco a reurbanização dessas áreas, considerando a hipótese de se trabalhar respeitando a complexidade da ocupação préexistente, tendo como referência a pesquisa de Duarte e Rocha (2006), baseada na Gramática da Forma o que, de per se, supõe a ruptura de padrões de moradia pré-estabelecidos, como no caso do PMCMV, cuja construção dentro de parâmetros de viabilidade econômica demanda processos inovadores, como é o caso da Fabricação Digital. (Nardelli, 2014)

Para tanto, a pesquisa percorreu dois caminhos concomitantes: capacitação da equipe na operação de processos de Fabricação Digital e busca de referências tecnológicas para a execução de edificações utilizando esse tipo de tecnologia, tendo como resultado a opção por trabalhar com processos de Fabricação subtrativos e adotar o sistema construtivo Wikihouse, de código aberto (open source), baseado numa licença creative-commons, iniciado em 2011 por Alastair Parvin e Nick Lerodiaconou e lançado na bienal de design de Gwangju, na Coreia do Sul.(Nardelli e Backheuser, 2016)

Para a capacitação dos envolvidos na pesquisa, foi adquirida uma máquina de corte, uma fresadora CNC (CNC Router), com o apoio da FINEP, que permite o corte de painéis de madeira, como compensados e laminados, isopores, entre outros materiais similares, além de metais não ferrosos. Dando-se, então, início a um programa de treinamento que incluiu tanto a capacitação em programas como RhinoCam e RhinoNest, necessários para a geração do código a ser enviado à máquina e melhor distribuição dos componentes 
que serão cortados no painel de madeira., quanto a operação da máquina, através da produção inicial de objetos mais simples, como mesas e cadeiras.

O resultado deste trabalho, já publicado, foi o projeto de uma residência unifamiliar de $36 \mathrm{~m} 2$ conforme prevista no PMCMV, adaptada, no entanto, ao sistema Wikihouse, baseado num modelo disponibilizado na página web da própria Wikihouse, identificado como Studio_v0.2., cujo sistema estrutural foi executado parcialmente em escala real. (Nardelli e Backheuser, 2016)

A execução desse protótipo proporcionou diversas reflexões no sentido de definir os próximos passos e, dentre os caminhos possíveis, identificou-se a necessidade de prosseguir o detalhamento do projeto da residência unifamiliar buscando, dentre outras, soluções construtivas para o sistema de vedação da moradia, compatíveis com a NBR 15.575/13, isto é, atendendo aos requisitos de segurança, habitabilidade e sustentabilidade, previstos naquela norma, bem como resolvendo as demandas das instalações hidráulicas e elétricas da edificação.

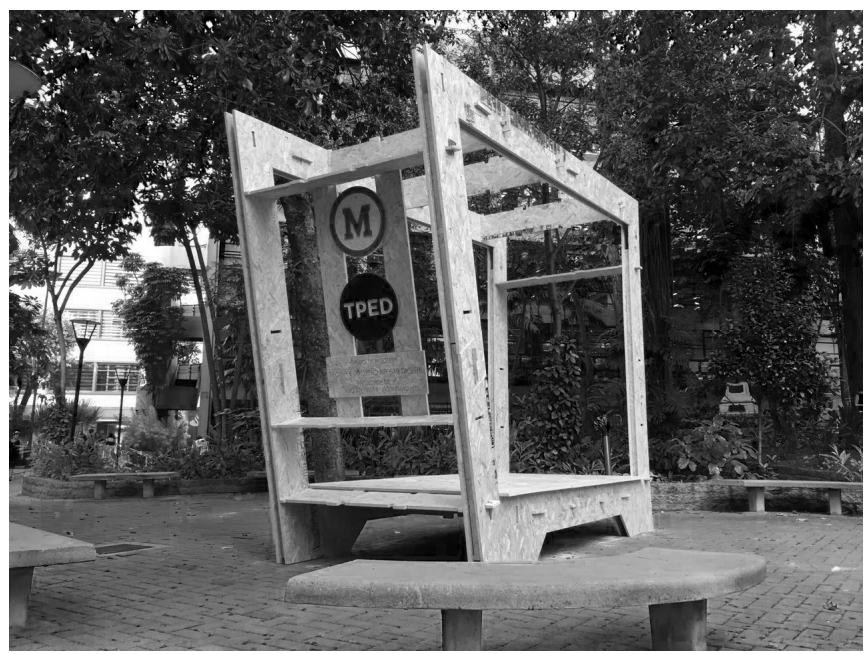

Figura 1: Protótipo fabricado em escala real, no experimento anterior

Por outro lado, ao longo do período de desenvolvimento da pesquisa, ampliou-se o olhar para além do PMCMV - na prática interrompido pela crise econômica em que o país mergulhou - e passou-se a considerar dois movimentos absolutamente distintos, porém convergentes em seus objetivos: o Maker Movement e a Autoconstrução.

O primeiro, Maker Movement, amplia as possibilidades técnicas do tradicional "faça-você-mesmo" norte-americano a partir da inserção de máquinas de controle numérico computadorizado em ambientes colaborativos de fabricação digital. (Hatch, 2014)

E o segundo, a Autoconstrução, consiste na prática dos próprios usuários construírem suas moradias, com os recursos disponíveis dentro de suas limitações e que se desenvolveu e persistiu no Brasil, em particular em São Paulo, desde os anos 60, tendo em vista a incapacidade do Estado brasileiro de solucionar essa enorme demanda através dos programas oficiais. (Maricato, 2014)

Essa produção autóctone, no entanto, sem a mediação de um profissional capacitado tecnicamente para orientá-la, tende a apresentar distorções e eventuais riscos aos seus usuários.

Assim, a hipótese deste trabalho é a de que seria possível atender parte dessa demanda, situada na faixa de menor renda e habitando áreas precárias, com um produto específico, desenvolvido de acordo com a Norma de Desempenho - NBR 15.575/13 - e apto a ser montado pelos próprios usuários, no tradicional sistema de mutirão, que caracteriza a Autoconstrução.

Numa palavra, uma "casa pacote", a ser comercializada num modelo de negócio específico para este público alvo.

\section{Definição conceitual do produto}

Um produto dessa natureza é composto por um conjunto interrelacionado de variáveis que precisam ser devidamente equacionadas, como segue:

- Programa: uma habitação padrão completa ou um módulo habitável mínimo e componível, que viabilizasse um processo evolutivo de construção de uma moradia.

- Tecnologia: sistema construtivo, materiais estruturais, de vedação e de acabamento e instalações complementares;

- Logística: a distribuição do produto feita a partir de um arquivo disponível na internet, como no sistema Open Desk - https://www.opendesk.cc/ - e executado sob demanda em oficinas de Fabricação Digital devidamente certificadas, ou seria fornecido um pacote pré-usinado, já pronto para a montagem. Num caso e no outro, como seria feita a entrega ao usuário e como seria realizada a montagem, de forma autônoma ou assistida - neste caso, eventualmente, contando com a aplicação da Lei de Assistência Técnica Gratuita, 11.888/08?

- $\quad$ Norma de Desempenho - NBR 15.575/13: esta norma, na verdade, articulou normas já existentes, das mais diversas disciplinas, com o objetivo de garantir a qualidade da construção de edificações habitacionais estabelecendo requisitos de segurança, habitabilidade e sustentabilidade.

- $\quad$ Composição de custos: o teto atual do valor dos imóveis para a Faixa 1 (até 3 salários mínimos), financiados pela CEF nas Regiões Metropolitanas de São Paulo, Rio de Janeiro e DF, é de $\mathrm{R} \$ 135.000,00$. Este, portanto, deveria ser o limite do preço de venda deste produto nestas praças, para que pudesse ser adquirido pelo usuário com base no financiamento subsidiado com juros de $5 \%$ a.a., previstos no PMCMV. 
Além disso, a definição destas variáveis precisa levar em consideração as regras estabelecidas pelas instituições governamentais para ter acesso ao crédito que, neste caso, limita-se à Caixa Econômica Federal que financia apenas os padrões pré-estabelecidos do PMCMV, i.e., Tipologia 1, casa térrea de $36 \mathrm{~m} 2$, com sala, cozinha, banheiro, circulação, 2 dormitórios e área externa com tanque e máquina ou Tipologia 2, apartamento de 39m2, sala, 1 dormitório para casal e 1 dormitório para duas pessoas, cozinha, área de serviço, banheiro.

Desse modo, dando continuidade ao trabalho já publicado anteriormente, o Grupo de Pesquisa decidiu seguir adiante adotando a Tipologia 1 desenvolvida no sistema Wikihouse, trabalhando com produtos certificados de acordo com a NBR $15.575 / 13$ e admitindo a hipótese de que o produto pudesse ser oferecido em arquivo digital, como no sistema OpenDesk, mas executado apenas em oficinas de Fabricação Digital devidamente certificadas e montado pelos usuários com supervisão técnica apoiada pela Lei 11.888/08, de Assistência Técnica Gratuita.

\section{Desenvolvimento do produto}

A partir da definição conceitual do produto, a sequência do trabalho já realizado priorizou o aprofundamento da solução tecnológica, focando nesta etapa, os sistemas de vedação, estudando possíveis soluções construtivas, desde os materiais a serem utilizados até os sistemas de encaixes para os caixilhos e esquadrias internas, bem como a compatibilização destes com os sistemas hidráulico e elétrico da moradia. Definições essenciais para o equacionamento posterior de todas as demais variáveis apresentadas acima, principalmente a composição final de custos.

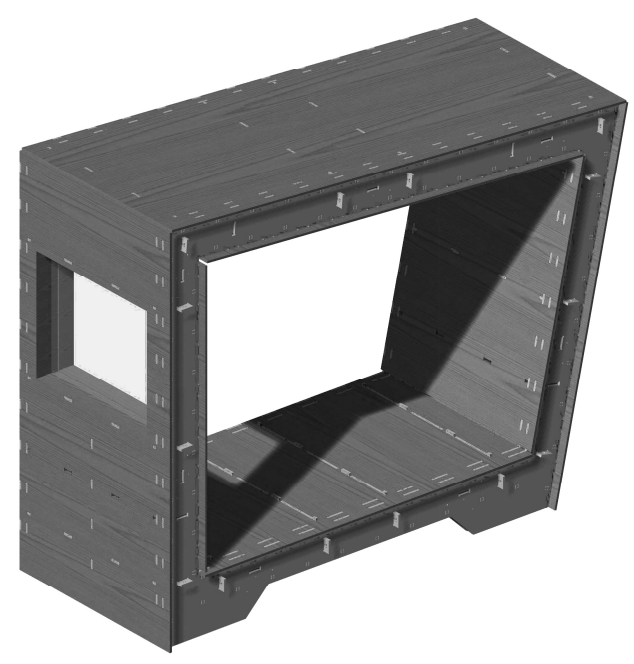

Figura 2: Projeto do pórtico já executado com as vedações

Neste sentido, uma análise técnica do protótipo parcialmente usinado apontou para a necessidade de simplificação dos encaixes, e uma adequação do sistema a elementos arquitetônicos disponíveis no mercado brasileiro, como chapas, janelas e portas já produzidas em série pela indústria.

A partir dessas diretrizes, estabeleceu-se uma classificação do sistema de vedação de acordo com a sua função na edificação e acabamento correspondente, resultando nas seguintes categorias e respectivas subdivisões:

- Vedações externas
a. Face externa pintada/Face interna pintada;
b. Face externa pintada/Face interna cerâmica;
c. Face externa cerâmica/Face interna cerâmica.

- Vedações internas
a. Face externa pintada/Face interna pintada;
b. Face externa pintada/Face interna cerâmica;
c. Face externa cerâmica/Face interna cerâmica.

Também foram identificados os componentes construtivos correspondentes ao tipo de fechamento, como segue:

- Painel cego

- Painel com abertura para janela

- Painel com abertura para porta

- Miolo
a. Vazio
b. Isolante termo acústico

E com relação às demandas das instalações elétricas e hidráulicas:

- Painéis com furação para tomadas

- Painéis com furação para tubulação de pequeno diâmetro

- Painéis com furação para tubulação de grande diâmetro

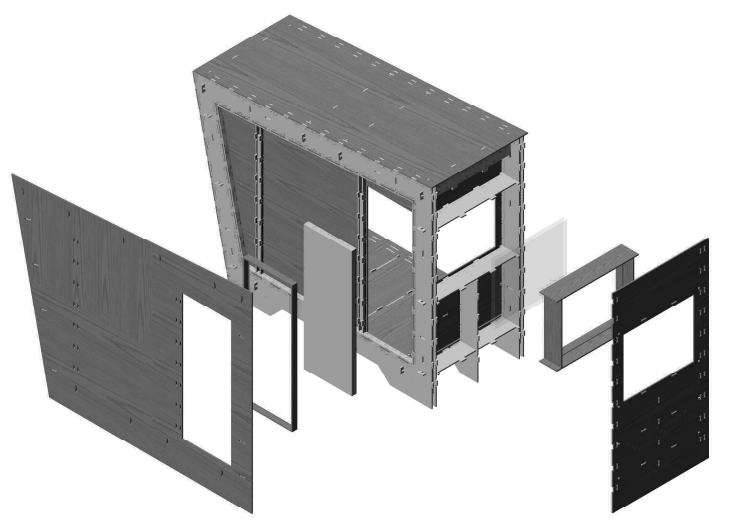

Figura 3: Componentes a serem desenvolvidos 
O passo seguinte foi a definição do material a ser utilizado para a produção desses painéis. Neste caso, além de nossa própria experiência, consideramos outros trabalhos realizados utilizando o sistema Wikhouse (Passaro e Rohde, 2015) e também sistemas construtivos "woodframe" já existentes no mercado, como o Sistema TecVerde http://www.tecverde.com.br/sistema-construtivo/ -, cujas instalações industriais visitamos durante o desenvolvimento desta pesquisa.

Concluímos, desse modo, que o sistema de vedação deveria ser formado por dois painéis contrapostos, constituindo as faces externa e interna dos fechamentos, produzidos em chapas OSB com tratamento anti-cupim, sobre as quais deve ser aplicada resina hidrófuga e acabamentos adequados às suas respectivas funções, conforme as categorias definidas anteriormente.

Assim, por exemplo. a superfície dos painéis que constituem a face externa das Vedações Externas, devem receber a aplicação de painéis cimentícios, sobre os quais é possível aplicar massa acrílica e pintura resistente às intempéries, enquanto a superfície dos painéis que constituem a face interna das Vedações Externas, devem receber gesso acartonado quando estão voltados para os ambientes de longa permanência e painéis cimentícios, quando estão voltados para as áreas úmidas, sobre os quais é possível colar revestimento cerâmico.

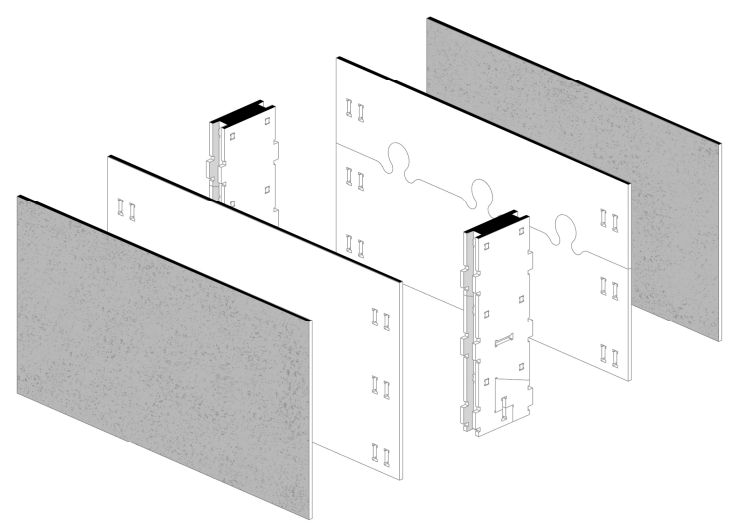

Figura 4: Elementos que compõem o sistema de vedação

No caso das Vedação Internas, as superfícies dos painéis que constituem ambas as faces devem receber gesso acartonado quando estão voltadas apenas para os ambientes de longa permanência e painéis cimentícios quando voltadas para as áreas úmidas para permitir a aplicação de revestimento cerâmico.

Com relação ao isolamento termo acústico, as Vedações Externas devem ter o Miolo preenchido com material isolante e as Vedações Internas podem manter o Miolo vazio.
O sistema se completa com a definição em projeto, dos painéis com diferentes configurações: cego, com vão luz para janelas e portas e com furações para tomadas e tubulações de pequeno ou grande diâmetro, de acordo com as demandas das instalações elétricas e hidráulicas.

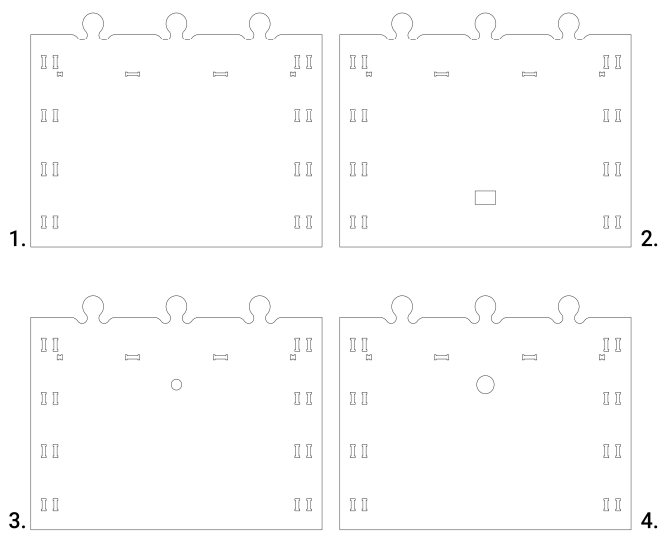

Figura 5: Diferentes configurações dos painéis do sistema de vedação

A partir destas definições, iniciou-se a modelagem dos painéis componentes deste sistema de vedação que, em seguida, serão usinados para a montagem de um protótipo experimental e validação dos encaixes e demais soluções de montagem destes painéis.

\section{Considerações Finais}

Os desequilíbrios sociais do Brasil seguirão, ainda por muito tempo, demandando soluções criativas tanto do mercado quanto, principalmente, das Instituições de Ensino e Pesquisa.

Neste sentido, é fundamental explorar novas possibilidades para resolver antigas demandas, como o déficit habitacional brasileiro. Soluções inovadoras não apenas do ponto de vista tecnológico, mas, também, do ponto de vista conceitual.

As profundas mudanças trazidas pelo desenvolvimento contínuo das Tecnologias da Informação e Comunicação, não se refletem somente nos processos de produção, mas têm provocado profundas mudanças de comportamento na sociedade.

Uma delas é a possibilidade cada vez mais acessível à população de produção dos próprios objetos de consumo, por meio da Fabricação Digital, que já se estabelece como tendência, através do Maker Movement. Neste contexto, insere-se a proposta da Wikihouse, que se propõe a ser uma plataforma de código aberto que permite a qualquer pessoa baixar o arquivo de uma casa e montá-la autonomamente.

Por outro lado, há muito tempo existe em nosso país o processo da Autoconstrução, em que a própria população procura solucionar a sua demanda, construindo em mutirões 
familiares moradias muitas vezes precárias, sem qualquer orientação técnica, que podem resultar em risco para seus moradores.

Nossa hipótese é que o desenvolvimento de uma unidade padrão de Habitação de Interesse Social utilizando o sistema Wikihouse pode atender a esse público com qualidade e de acordo com as normas técnicas que garantem a segurança do ambiente construído.

No entanto, o desenvolvimento deste produto é uma tarefa complexa que exige o cumprimento de diversas etapas, desde a sua formulação conceitual até a sua fabricação e disponibilização aos usuários finais.

O primeiro passo foi dado ao produzirmos um protótipo do sistema de pórticos estruturais da unidade padrão de HIS e, neste momento, estamos envolvidos com o desenvolvimento do sistema de vedação dessa unidade.

Resolvida essa etapa, vamos nos concentrar nas instalações hidráulicas e elétricas e na cobertura da unidade, para então podermos elaborar a composição de custos que permita a este produto inserir-se nas normas já existentes de financiamento de Habitações de Interesse Social no Brasil.

\section{Agradecimentos}

Agradecemos à Financiadora de Estudos e Projetos (FINEP), aos membros do Grupo de Pesquisa Teoria e Projeto na Era Digital e à direção da empresa TecVerde, na pessoa de seu director Caio Bonatto, que muito gentilmente nos recebeu e ofereceu todas as informações necessárias à continuidade desta pesquisa.

\section{Referencias}

Duarte, José P. e Rocha, João. 2006. A grammar for the Pátio Houses of the Medina of Marrakech, towards a tool for housing design in Islamic Contexts. In: Bourdakis, Vassilis and Charitos Dimitris (eds), Proceedings of the 24th Conference on Education in Computer Aided Architectural Design in Europe 2006, Volos, Greece.

Desempenho de edificações habitacionais: guia orientativo para atendimento à norma ABNT NBR 15575/2013./Câmara Brasileira da Indústria da Construção. -Fortaleza: Gadioli Cipolla Comunicação, 2013.

Guia para Arquitetos na Aplicação da Norma de Desempenho ABNT NBR 15575/2013./ Associação Brasileira dos Escritórios de Arquitetura - AsBEA, 2015

Hatch, Mark (2014) - The Maker Movement Manifesto, rules for innovation in the new world of crafters, hackers and tinkerers. Mc Graw Hill Education, 2014

Nardelli, Eduardo Sampaio (2014) - Fabricação Digital na Produção de Habitação de Interesse Social no Brasil [Digital Fabrication in Social Housing Production of Brazil] SiGraDi 2014 [Proceedings of the 18th Conference of the Iberoamerican Society of Digital Graphics - ISBN: 978-9974-99-655-7] Uruguay Montevideo 12 - 14 November 2014, pp. 350-353

Nardelli, Eduardo Sampaio; Backheuser, Luiz Alberto Fresl (2016) Sistema Wikihouse aplicado ao Programa Minha Casa Minha Vida [Wikihouse System applied to the Minha Casa Minha Vida
Program] SIGraDi 2016 [Proceedings of the 20th Conference of the Iberoamerican Society of Digital Graphics - ISBN: 978-9567051-86-1] Argentina, Buenos Aires 9 - 11 November 2016, pp.297-304

Rolnik, R. (2010). Minha Casa, Minha Vida: a dificuldade de atender às famílias de menor renda. Blog da Raquel Rolnik. Recuperado em 5 de agosto de 2010, de http://raquelrolnik. wordpress.com/.

Passaro, Andrés; Rohde, Clarice (2015) - House Magazine: open source architecture - SIGRADI 2015 [Proceedings of the 19th Conference of the Iberoamerican Society of Digital Graphics - vol. 1 - ISBN: 978-85-8039-135-0] Florianópolis, SC, Brasil 23-27 November 2015, pp. 70-76. 